\title{
Tumor characteristics linked to radiation
}

It is known that radiation can cause cancer by damaging DNA. According to a recently published study, radiation might also induce other molecular changes in surrounding tissue. Such molecular changes were associated with accelerated tumor growth and with the development of a particularly aggressive type of breast cancer in a mouse model of breast cancer (Cancer Cell 19, 640-651; 2011).

Mary Helen Barcellos-Hoff of the New York University School of Medicine and colleagues exposed a group of 10 - to 12 -week-old mice to whole-body radiation at doses of 10-100 cGy. Three days later, they transplanted oncogenic tissue into the mammary glands of mice that had received radiation and mice that had received sham radiation. Tumors developed more quickly in mice that had been exposed to radiation; higher radiation doses were associated with increased tumor growth rates. Additionally, more of the tumors in irradiated mice were estrogen-receptor negative, a marker associated with aggressive breast cancer. By one year after transplantation, tumors

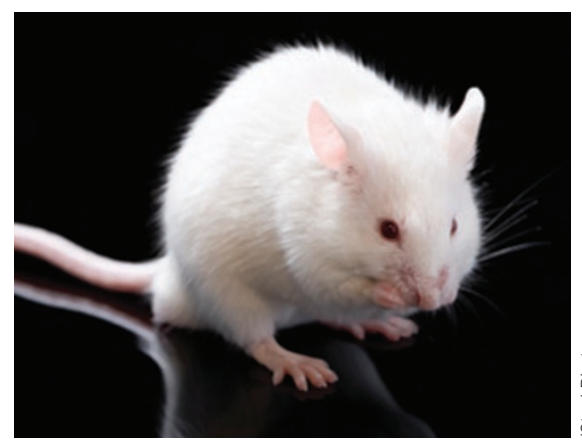

had developed in all of the mice that had received radiation and in $69 \%$ of mice that had received sham radiation.

The team found that radiation led to the persistent activation of a protein called TGF $\beta$, which is known to have a role in the response of tissues to radiation. Analyses showed that the radiation dose elicited a change in gene expression, most of which was dependent on the level of TGF $\beta$. When the researchers irradiated mice in which TGF $\beta$ gene activity had been genetically reduced, the irradiation did not affect the frequency, latency or growth rate of estrogen-receptor-negative tumors. Put together, these data suggest that chronic TGF $\beta$ activity is the mechanism by which host irradiation accelerates mammary tumor growth in these mice. Further analysis revealed that radiation led to other molecular changes that were associated with the increased frequency of estrogenreceptor-negative tumors in mice exposed to radiation. These molecular changes were independent of the increased TGF $\beta$ gene activity associated with accelerated tumor growth.

Several features of the cancer in mice that had received radiation parallel those found in women with breast cancer who had received radiotherapy for childhood cancer. Such features include early onset cancer, a more aggressive tumor phenotype and markers associated with a worse prognosis. The authors conclude that the elevated cancer risk associated with radiation therapy potentially could be decreased by targeting host biology after radiation.

Kirsten Dorans

\section{HOW LOW CAN WORMS GO?}

Bacteria-eating worms dwell in treasure caves deep below the earth's surface, where only single-celled organisms were thought to exist. Although it may sound like the premise of a sci-fi masterpiece, this scenario is the major finding of a recent report in Nature. The report describes the discovery of four species of nematodes, or roundworms, in the depths of South African gold mines, where conditions could charitably be called inhospitable. The worms were recovered from fracture water used to flush mine boreholes at depths of 0.9-3.6 km. In the boreholes where the worms were found, ambient temperatures were $24-48{ }^{\circ} \mathrm{C}$, well above the tolerance range of most terrestrial nematodes. The environments were also hypoxic, with aqueous $\mathrm{O}_{2}$ concentrations ranging from $13 \mu \mathrm{M}$ to $72 \mu \mathrm{M}$.

One of the species recovered by the research team, which was led by Gaetan Borgonie (Ghent University, Belgium) and Tullis Onstott (Princeton University, NJ), has never before been described. Because it was discovered deep underground, the new nematode was named Halicephalobus mephisto, alluding to the Faustian lord of the underworld Mephistopheles. H. mephisto is roughly $0.5 \mathrm{~mm}$ long with a ringed body and relatively long tail (Nature 474, 79-82; 2011). The known species Plectus aquatilis was recovered from a different mine, along with a monhysterid nematode. DNA of a fourth nematode, also a monhysterid species, was recovered from a third location.

All three living species preferred to feed on indigenous bacteria from the mines rather than Escherichia coli. The native bacteria typically exist in biofilms that require time to become established, suggesting that there is a functioning ecosystem at depth in the mines.

Scientists are now wondering how widespread such communities are and how long they have existed. Borgonie, Onstott and their colleagues hope to continue investigating the complexity of underground ecosystems and to sequence the genomes of the recovered worms, looking for clues as to whether the worms have evolved in the subterranean environments. Onstott spoke with Nature News about the future research. "That could tell us a lot about evolution," said Onstott. "Is H. mephisto endowed with any special capabilities? Is it more primitive? Has it acquired attributes that imply adaptation and evolution in the subsurface?"

The current results show that deep underground ecosystems are more complex than previously thought. They also suggest the possibility that similarly complex communities could exist in subsurface environments in other locations on earth, or even on other planets in our solar system. 